\title{
Comment
}

\section{Ética: Normas e Princípios para uma Sociedade mais Empática}

Ronaldo Bezerra dos Santos ${ }^{1}$

\begin{abstract}
Resumo: Ética e filosofia guardam profunda correlação. A visão do homem como um ser social e histórico é uma concepção filosófica que representa o fundamento da ética. Os conceitos de liberdade, necessidade, valor, consciência, são objeto de estudo da ética e são antecedidos de uma explicação filosófica. As relações humanas em sociedade também dizem respeito à ética, cuja inserção nesse contexto se dá através da sociabilidade. São os parâmetros sociais adotados por determinada sociedade que irão nortear a vida do indivíduo e lhe permitir conviver com outras pessoas.
\end{abstract}

Palavras-chave: Ética. Filosofia. Moral. Valor. Sociedade

\section{Ethics: Norms and Principles for a More Empathic Society}

\begin{abstract}
Ethics and philosophy hold a deep correlation. The vision of man as a social and historical being is a philosophical conception that represents the foundation of ethics. The concepts of freedom, necessity, value, conscience, are the object of study of ethics and are preceded by a philosophical explanation. Human relations in society also concern ethics, whose insertion in this context is through sociability. They are the social parameters adopted by a certain society that will guide the life of the individual and allow him to live with other people.
\end{abstract}

Keywords: Ethics. Philosophy. Moral. Value. Society

\section{Introdução}

O desenvolvimento do ser humano está intimamente ligado à interatividade, o que acontece através da socialização com os demais indivíduos ao longo do seu ciclo vital. É através dessa interatividade que acontece a satisfação das suas necessidades, a assimilação da cultura e, reciprocamente, o desenvolvimento e a perpetuação da sociedade. Essa socialização se dá através de um processo que tem inicio desde o seu nascimento. Ela é permeada por uma série de fatores sujeitos a alterações durante esse percurso. E é justamente isso que se vem observando nas últimas décadas: mudanças significativas nas tecnologias, nas comunicações, o aumento na disponibilidade de informações, as famílias caracterizando-se a partir de novas configurações, entre outras.

\footnotetext{
${ }^{1}$ Licenciado em Historia - URCA - Especialização em Historia e Sociologia - URCA - Mestrando em Ciência da Educação - Programa de Mestrado internacional em Educação Anne Sullivan University - Profronaldo62@ hotmail.com
} 
Id on Line Revista Multidisciplinar e de Psicoloqia

Id on Line Multidisciplinary and Psycology Journal

Com uma função preponderante a escola se insere nesse contexto como grande auxiliar na consolidação desse processo de socialização.

A escola será determinante para o desenvolvimento cognitivo e social infantil e, portanto, para o curso posterior de sua vida. É na escola que se constrói parte da identidade de ser e pertencer ao mundo; nela adquirem-se os modelos de aprendizagem, a aquisição dos princípios éticos e morais que permeiam a sociedade; na escola depositam-se as expectativas, bem como as dúvidas, inseguranças e perspectivas em relação ao futuro e às suas próprias potencialidades. (BORSA, 2007, p. 1-2).

A pertença do indivíduo, desde o seu nascimento, a um determinado grupo social, do qual passa a ser membro, concretiza-se pelo fato de suas necessidades básicas estarem ligadas necessariamente às outras pessoas, de onde subjaz o entendimento de que tais necessidades deverão ser satisfeitas em sociedade. Por outro lado a manutenção e sobrevivência do grupo social ao qual pertence o indivíduo estão ligadas à sua incorporação ao mesmo, o que se dá através da transmissão da cultura a qual,

Envolve valores, normas, costumes, atribuição de papéis, ensino da linguagem, habilidades e conteúdos escolares, bem como tudo aquilo que cada grupo social foi acumulando ao longo da historia e que é realizado através de determinados agentes sociais que são encarregados de satisfazer as necessidades da criança e incorporá-la ao grupo social. (Ibidem, p. 2).

À interatividade, à incorporação, ao envolvimento, à satisfação das suas necessidades básicas, à transmissão e assimilação da cultura, à perpetuação da sociedade se interliga um elemento cuja essência é primordial para o bom andamento, o desenvolvimento e o bem estar das relações que envolvem esses fatores: a ética. Ética como pressuposto de comportamento lógico, de convivência racional, de empatia, de respeito à cidadania, ao meio ambiente, enfim de compreensão de vida saudável em coletividade. Com referência à ética nas relações de um modo geral BOFF nos adverte que

Atualmente quase todas as sociedades estão enfermas, produzem má qualidade de vida para todos, seres humanos e demais seres da natureza. E não poderia ser diferente, pois estão assentados sob modo de ser do trabalho entendido como dominação e exploração da natureza e da força do trabalhador. A exceção de sociedades originárias como aquelas dos indígenas e de outras minorias no sudeste da Ásia, da Oceania e do Ártico, todas são reféns de um tipo de desenvolvimento que apenas atende as necessidades de uma parte da humanidade (os países industrializados), deixando os 


\begin{abstract}
demais na carência, quando não diretamente na fome e na miséria. Somos espécie que se mostrou capaz de oprimir e massacrar seus irmãos e irmãs da forma mais cruel e sem piedade. Só neste século morreram em guerras, em massacres e em campos de concentração cerca de 200 milhões de pessoas. E ainda degenera e destrói sua base de recursos naturais não renováveis.

(...) Não há só a rede de relações sociais. Existem as pessoas concretas, homens e mulheres. Como humanos, as pessoas são seres falantes; pela fala constroem o mundo com suas relações. Por isso o ser humano é, na essência, alguém de relações ilimitadas. $\mathrm{O}$ eu somente se constrói mediante a dialogação com o tu, como o viram psicólogos modernos e, anteriormente, filósofos personalistas. O tu possui uma anterioridade sobre o eu. O tu é o parteiro do eu. Mas o tu não é qualquer coisa indefinida. É concretamente um rosto com olhar e fisionomia. O rosto do outro torna impossível a indiferença. O rosto do outro me obriga a tomar posição porque fala, provoca, evoca e convoca. Especialmente o rosto do empobrecido, marginalizado e excluído.
\end{abstract}

A dimensão da ética transcende a todo e qualquer pensamento subjetivista. A ética aflora a partir da concepção do desprezar o eu egoístico para viver o tu partilhado. É a compreensão de que o outro é a extensão do eu.

\title{
Conceituando Ética
}

Desde a Antiguidade, mais especificamente a Antiguidade Clássica, o uso da palavra ética faz parte do cotidiano de todas as sociedades tenham ou não, essas, normas, leis, códigos, diretrizes, escritos ou orais, que norteiem o bom andamento, a convivência, as relações dos seus membros em toda e qualquer área do seu desenvolvimento. Etimologicamente descreve-se ética como um termo advindo "da palavra grega 'ethike', cujo étimo grego é "ethos", significando este último "costume” ou 'hábito'." (? CIBERDÚVIDAS DA LÍNGUA PORTUGUESA, 2002).

Há uma inclinação tendenciosa de se confundir ética com moral, porém,

\begin{abstract}
Moral advém da palavra latina "moralis" mas que, embora detenha um étimo plausível na palavra latina "more" (que também significa "costume" ou "hábito"), não surgiu como evolução desse possível étimo, mas sim como uma espécie de neologismo então introduzido por Cícero ao traduzir a palavra grega "éthikos" que significa "relativo aos costumes". (? CIBERDÚVIDAS DA LÍNGUA PORTUGUESA, 2002).
\end{abstract}

A palavra moral em português é derivada da tradução latina do termo grego ethos, cuja tradução romana se lê "mor-morus", significando "costume mor" ou "costume superior". 
Ao longo dos séculos a ética no dia a dia das sociedades tem ocupado cada vez mais lugar de destaque no estudo da filosofia principalmente em vista da expansão em que esta se encontra, e em especial quando se trata do pensamento sobre a ação, o que induz a uma distinção mais aprimorada entre ética e moral.

No século XX o filósofo espanhol Adolfo Sánches Váques cria uma famosa diferenciação entre os dois conceitos. Para ele o termo oral se refere a uma reflexão que a pessoa faz de sua própria ação. Já o termo ética abrange o estudo dos discursos morais, bom como os critérios de escolha para valorizar e padronizar as condutas numa família, empresa ou sociedade. (MEUCCI, 2013).

Socialmente falando o que é afinal ética, moral, conduta correta, virtuosa? Há nesse contexto respostas e definições múltiplas visto que há uma homogeneidade de pontos de vista para defini-los. "Marxistas, liberais, muçulmanos, psicanalistas, jornalistas e políticos, agem e valorizam as ações de modo diferente. Porém, todos eles lutam pela definição mais legítima de uma "boa ação" ou da "ação correta". (Meucci, 2013).

\begin{abstract}
Uma das possíveis definições de ética seria a de que é uma parte da filosofia (e também pertinente às ciências sociais) que lida com a compreensão das noções e dos princípios que sustentam as bases da moralidade social e da vida individual. Em outras palavras, trata-se da reflexão sobre o valor das ações sociais consideradas tanto no âmbito coletivo como no âmbito individual. (RIBEIRO - BRASIL ESCOLA).
\end{abstract}

Foi na cultura ocidental que pela primeira vez, no período Clássico da Idade Antiga, os primeiros grandes filósofos - Sócrates, seguido de Platão e Aristóteles - passaram a analisar de forma crítica e reflexiva os valores e costumes da época. Detiveram-se em seus estudos sobre a compreensão do que seriam valores universais, correção, virtuosidade e ética. O ambiente mostrava-se propício, pois vivia-se um contexto histórico de grande efervescência política.

\title{
Ética e Filosofia
}

O modo de ser e agir dos seres humanos, seus comportamentos e caráter, sua moralidade são fatores na vivência do seu cotidiano que formam o objeto de estudo da ética, campo da filosofia que se detém em estudar 
Os valores que regem os relacionamentos interpessoais, como as pessoas se posicionam na vida e de que maneira elas convivem em harmonia com as demais. $\mathrm{O}$ termo ética é oriundo do grego, e significa "aquilo que pertence ao caráter. A ética diferencia-se da moral, uma vez que, a moral é relacionada a regras e normas, costumes de cada cultura, e a ética é o modo de agir das pessoas. (SIGNIFICADOS, 2011).

Pode-se dizer que a Revolução Industrial foi o divisor de águas com relação à filosofia clássica e a filosofia contemporânea, entremeadas pela filosofia medieval, a filosofia renascentista e a filosofia moderna. A filosofia clássica, representada em Sócrates, Platão Aristóteles, Epicuro, Anaximandro, Pitágoras, Ptolomeu, Cícero, Sêneca, Tales, entre outros abrangia áreas como a estética, a psicologia, a sociologia, a pedagogia, a economia, a política... Com a Revolução Industrial, e consequentemente a expansão das relações a nível mundial, surgiu a filosofia contemporânea, tendo como seus principais representantes entre os século XIX e XX: G W F Hegel, Arthur Schopenhauer, Augusto Comte, Sören Kierkegaard, Karl Marx, Charles Sanders Peirce, William James, Friedrich Nietzsche, Sigmund Freud, Edmund Husserl, Henri Berqson, Bertrand Russel, Carl G Junq, Ludwiq Wittqenstein, Martin Heideqqer, Max Horkheimer, Jean Piaget, Jean-Paul Sartre, Maurice, Merleau Ponty, Claude Lévi Strauss, Antonio Gramsi, Henri Lefebvre, Michel Foucault e outros.

De acordo com a descrição de Chauí (2008, p. 16)

\begin{abstract}
A filosofia não é ciência: é uma reflexão crítica sobre os procedimentos e conceitos científicos. Não é religião: é uma reflexão crítica sobre as origens e formas das crenças religiosas. Não é arte; é uma interpretação crítica dos conteúdos, das formas, das significações das obras de arte e do trabalho artístico. Não é sociologia nem psicologia, mas a interpretação e avaliação crítica dos conceitos e métodos da sociologia e da psicologia. Não é política, mas interpretação, compreensão e reflexão sobre a origem, a natureza e as formas do poder. Não é história, mas interpretação do sentido dos acontecimentos enquanto inseridos no tempo e compreensão do que seja o próprio tempo. Conhecimento do conhecimento e da ação humanos, conhecimento da ação temporal dos princípios do saber e do agir, conhecimento da mudança das formas do real ou dos seres, a Filosofia sabe que está na Historia e que possui uma historia.
\end{abstract}

De acordo com Platão os seres humanos deveriam se beneficiar diretamente da filosofia, pois ela é o verdadeiro saber. Para Descartes filosofia é a perfeita sabedoria que contém todo o conhecimento a ser alcançado pelos homens para sua vida como um todo e no campo das técnicas e das artes. A filosofia para Kant tem como fim último levar o homem a ser feliz através do conhecimento que a razão pode adquirir de si mesma "para saber o que pode conhecer e o 
que pode fazer". Marx afirmou ter estado ela em estado contemplativo por um longo tempo, agora iria conhecer o mundo para transformá-lo, com isso todos conheceriam a justiça, a abundância e a felicidade. Merleau-Ponty coloca-a como uma condição para o homem abrir sua mente e transformar tudo ao seu redor. Todos que almejarem liberdade e felicidade devem procurar a filosofia, embora seja um caminho tortuoso, diz Espinoza.

A palavra filosofia tem sua origem em duas palavras gregas: philo, que se deriva de philia, e significa amizade, amor fraterno, respeito entre os iguais, e sophia, sabedoria, que por sua vez vem de sophos, que quer dizer sábio. Quem idealizou a palavra filosofia foi o filósofo grego Pitágoras de Samos, no século V a.C. Os homens tornar-se-iam filósofos amando e desejando a sabedoria plena, embora seja ela um objeto dos deuses, afirmou Pitágoras.

Dizia Pitágoras que três tipos de pessoas compareciam aos jogos olímpicos (a festa mais importante da Grécia): as que iam para comerciar durante os jogos, ali estando para servir os seus próprios interesses e sem preocupação com as disputas e os torneios; as que iam para competir, isto é, os atletas e artistas (pois durante os jogos também havia competições artísticas: dança, poesia, música, teatro), e as que iam para contemplar os jogos e torneios, para avaliar o desempenho e julgar o valor dos que ali se apresentavam. Esse terceiro tipo de pessoa, dizia Pitágoras, é como o filósofo. (CHAUÍ, 2008, p. 19).

Assim afirmando Pitágoras enaltece a figura do filósofo, imputando-lhe desprendimento do mundo material, desinteresse pela competição intelectual, ao mesmo tempo em que só uma coisa lhe basta: o saber, que lhe proporciona "observar, contemplar, julgar e avaliar as coisas, as ações, a vida", o que só pode ser feito com os olhos do espírito.

As grandes questões e problemas com relação ao conhecimento, verdade, existência, linguagem e valores são estudados pela filosofia. E nesta abordagem, os argumentos racionais tornam esse segmento especial e diferente da mitologia e religião. Há métodos importantes utilizados como experiência de pensamento, argumentação lógica. A seguir apresentamos uma tabela, com alguns dos maiores filósofos da história. 
Id on Line Revista Multidisciplinar e de Psicologia

Id on Line Multidisciplinary and Psycology Journal

Tabela 1 - Filósofos e suas frases famosas.

\begin{tabular}{l|l}
\hline \multicolumn{1}{c|}{ Filósofo } & \multicolumn{1}{c}{ Frase } \\
\hline Blaise Pascal (623-1662) & $\begin{array}{l}\text { O Pensamento faz a grandeza do homem } \\
\text { "O coração tem razões que a própria razão } \\
\text { desconhece”. }\end{array}$ \\
\hline Santo Agostinho (354-430) & $\begin{array}{l}\text { A verdadeira medida do amor é não ter } \\
\text { medida }\end{array}$ \\
\hline Immanuel Kant (1724-1804) & $\begin{array}{l}\text { A boa vontade é condição indispensável para } \\
\text { sermos dignos de felicidade }\end{array}$ \\
\hline Jean-Jacques Rousseau (1712-1778) & $\begin{array}{l}\text { Geralmente aqueles que sabem pouco falam } \\
\text { muito e, aqueles que falam muito sabem } \\
\text { pouco. }\end{array}$ \\
\hline Euclides (360 a.C.-295 a.C.) & $\begin{array}{l}\text { O número é uma pluralidade composta de } \\
\text { unidades }\end{array}$ \\
\hline Friedrich Nietzche (1844-1900) & $\begin{array}{l}\text { Não há fatos eternos, como não há verdades } \\
\text { absolutas }\end{array}$ \\
\hline René Descartes (1596-1650) & Penso, logo existo \\
\hline Platão (428 a.C. -347 a.C.) & $\begin{array}{l}\text { Quem comete uma injustiça é sempre mais } \\
\text { infeliz que o injustiçado }\end{array}$ \\
\hline Aristóteles (384 a.C. - 399 a.C.) & $\begin{array}{l}\text { O ignorante afirma, o sábio duvida, o sensato } \\
\text { reflete. }\end{array}$ \\
\hline Sócrates (470 a.C. - 399 a.C.) & Só sei que nada sei \\
\hline
\end{tabular}

\section{Acerca da Ética na Convivência Social e nas Relações Humanas}

Toda e qualquer sociedade estruturada dentro dos parâmetros normais, cujas características se embasam em fatores que sejam propícios, que satisfaçam o mínimo das necessidades de seus cidadãos, sem dúvida se rege por um código moral que exerce influência sobre a subjetividade de cada um. Através da observância da ética, portanto, seria possível concluir até que ponto se estaria sendo fiel a esse código de conduta, o qual estaria em consonância com os ditames da sociedade. Que valor se estaria atribuindo aos valores adotados por ela. Ribeiro comenta que:

Segundo alguns filósofos, nossas vontades e nossos desejos poderiam ser vistos como um barco à deriva, o qual flutuaria perdido no mar, o que sugere um caráter de inconstância, Essa mesma inconstância tornaria a vida social impossível se nós não tivéssemos alguns valores que permitissem nossa vida em comum, pois teríamos um verdadeiro caos. Logo, é necessário educar nossa vontade, recebendo uma educação 
(formação) racional, para que dessa forma possamos escolher de forma acertada entre o justo e o injusto, entre o certo e o errado.

Depreende-se, portanto, que a observância da ética pressupõe nosso autopoliciamento, o que se daria como consequência de uma educação imbuída de racionalidade, pois a opção entre ordem e caos é feita através do predomínio da razão.

Esse influxo da racionalidade nas escolhas das diversas situações que se nos apresentam é consequência dos juízos de fato e dos juízos de valor. Chauí (2008, p. 431) assim se reporta quanto a esses juízos:

Juízos de fato são aqueles que dizem o que as coisas são, como são e porque são. Em nossa vida cotidiana, mas também na metafísica e nas ciências, os juízos de fato estão presentes. Diferentemente deles, os juízos de valor - avaliações sobre coisas, pessoas e situações - são proferidos na moral, nas artes, na política, na religião.

Juízos de valor avaliam coisas, pessoas, ações, experiências, acontecimentos, sentimentos, estados de espírito, intensões e decisões como bons ou maus, desejáveis ou indesejáveis,

Os juízos éticos de valor são também normativos, isto é, anunciam normas que determinam o dever ser de nossos sentimentos, nossos atos, nossos comportamentos. São juízos que enunciam obrigações e avaliam intensões e ações segundo o critério do correto e do incorreto.

Os juízos éticos de valor nos dizem o que são o bem, o mal a felicidade. Os juízos éticos normativos nos dizem que sentimentos, intensões, atos e comportamentos devemos ter ou fazer para alcançar o bem e a felicidade. Enunciam também que atos, sentimentos, intensões e comportamentos são condenáveis ou incorretos do ponto de vista moral.

Como podemos observar os juízos de fato e os juízos de valor possuem origem antagônica. Um origina-se da natureza, enquanto o outro tem na cultura a sua origem. A natureza por si só acontece, independente da interferência humana, pois foi constituída para tal. Por outro lado a interferência do homem na natureza, "acrescentando-lhe sentidos novos, intervindo nela, alterando-a através do trabalho, e da técnica, dando-lhe valores" (ibidem, p. 432), dá origem a cultura, operando uma autointerpretação, ao mesmo tempo em que interpreta suas relações com a natureza. 
Id on Line Revista Multidisciplinar e de Psicologia

Id on Line Multidisciplinary and Psycology Journal

\section{Considerações Finais}

O certo e o errado, o bem e o mal, o justo e o injusto, são fatores que norteiam a vida do homem desde o seu surgimento e sobre os quais é impulsionado a refletir para uma tomada de decisão, ou seja, para escolher o que adotar em determinadas circunstâncias que assim o requeiram. Nesse contexto o indivíduo deve levar em consideração as diretrizes, os parâmetros pelos quais se rege a sociedade da qual ele é integrante e através dos quais ele interage e se sociabiliza com as outras pessoas.

\footnotetext{
A ética é uma disciplina teórica sobre uma prática humana, que é o comportamento moral... A ética tem também preocupações práticas. Ela orienta-se pelo desejo de unir o saber ao fazer. Como filosofia prática, isto é, disciplina teórica com preocupações práticas, a ética busca aplicar o conhecimento sobre o ser para construir aquilo que deve ser. (COTRIM, 2004, p. 264).
}

Os valores e as qualidades humanas positivos são conceitos pelos quais o indivíduo deve sempre estar em busca constante, procurando se pautar pelos mesmos, pois, ética pressupõe a observância e o cumprimento desses valores, visto que eles formam a base para as relações humanas, o que também diz respeito às relações sociais dos homens, tendo em vista que os conceitos filosóficos embasam a justiça e o direito na ética.

\section{Referências}

BOFF, Leonardo. Saber Cuidar: Ética do Humano - Disponível em: < file:///D:/Users/Usuario/Downloads/2++Saber+Cuidar++Etica+do+Humano+A+ETICA+DO+CUIDADO\%20(2).pdf $>$ Acessado em: 15 de set de 2016

BORSA, Juliane Callegaro. O Papel da Escola no Processo de Socialização Infantil - O Portal dos Psicólogos - 2007 - Disponível em: <http://www.psicologia.pt/artigos/textos/A0351.pdf> Acessado em: 13 de set de 2016

CHAUI, Marilena. Convite à Filosofia. Ed. Ática, São Paulo. 2000. Disponível em:< http://home.ufam.edu.br/andersonlfc/Economia_Etica/Convite\%20\%20Filosofia\%20\%20Marilena\%20Chaui.pdf> Acessado em: 25 de set de 2016 
Id on Line Revista Multidisciplinar e de Psicologia

Id on Line Multidisciplinary and Psycology Journal

COTRIM, Gilberto. Fundamentos de Filosofia. 15ª Ed. São Paulo: Saraiva, 2004.

LUCAS, Adriano. Top 10 Maiores Filósofos de Todos os Tempos. Disponível em: <http://top10mais.org/top-10-maiores-filosofos-de-todos-os-tempos/> Acessado em: 25 de set de 2016

MEUCCI, Artur. Filosofia, Psicanálise e Educação. Disponível em< http://meucci.com.br/oconceito-de-etica/ - artur Meucci - Filosofia, psicanálise e educação - Ética - O Conceito de Ética> Acessado em: 20 de set de 2016

RIBEIRO, Paulo Silvino. O Que É Ética. Disponível em:<http://brasilescola.uol.com.br/sociologia/o-que-etica.htm > Acessado em: 20 de set de 2016

SANTOS, Joelma Coêlho dos. et ali. Consciência Política - Filosofia, Ética e Sociedade. Disponível em: <http://www.portalconscienciapolitica.com.br/products/filosofia-etica-esociedade/> Acessado em: 15 de set de 2016

SIGNIFICADOS. Significado de Ética na Filosofia. Disponível em:< https://www.significados.com.br/etica-na-filosofia/> Acessado em: 23 de set de 2016

UOL EDUCAÇÃO. Pesquisa Escolar - Filosofia Contemporânea (1): Principais Filósofos Contemporâneos. 2006. Disponível em: <http://educacao.uol.com.br/disciplinas/filosofia/filosofia-contemporanea-1-principaisfilosofos-contemporaneos.htm-> Acessado em: 25 de set de 2016

CIBERDÚVIDAS da Língua Portuguesa. "Ética” e "Moral”: etmologia. Disponível em: <https://ciberduvidas.iscte-iul.pt/consultorio/perguntas/etica-e-moral-etimologia/9599> Acessado em: 18 de set de 2016

\section{Como citar este artigo (Formato ABNT):}

SANTOS, Ronaldo B. Ética: Normas e princípios filosóficos para uma sociedade mais empática. Id on Line Revista Multidisciplinar e de Psicologia, Fevereiro de 2017, vol.11, n.34, p. 94-103. ISSN: 1981-1179.

Recebido: 04.10.2016

Aceito: 27.01.2017 